\title{
Risk-Adjustment in Long-Term Health Insurance Contracts in Germany
}

\author{
Johann Eekhoff, Markus Jankowski and Anne Zimmermann* \\ University of Cologne, Economic Policy Departement, Albertus-Magnus-Platz, D-50923 Cologne, \\ Germany. \\ E-mail: j.eekhoff@uni-koeln.de, markus.jankowski@online.de, and Zimmermann@wiso.uni-koeln.de
}

In the private health insurance (phi) market in Germany ageing provisions are used to reduce age-related premium increases in long-term contracts. Currently, the provisions are not transferred if the insured person switches to another provider. Thus, there are no incentives for the insured to cancel their old policy because they would have to pay higher premiums for the same services under a new contract due to higher age and the loss of their ageing provisions. There is a long-standing discussion if it is possible to intensify competition on the phi-market in Germany. The main question is whether the transferring of ageing provisions would lead to risk selection or not. We have reconsidered Meyer's model of transferable risk-adjusted ageing provisions. ${ }^{1}$ It has been shown that it is indeed possible to prevent risk selection in a competitive phi-market. We will present a number of counter-arguments to the most frequently stated criticism of the model. ${ }^{2}$

The Geneva Papers (2006) 31, 692-704. doi:10.1057/palgrave.gpp.2510097

Keywords: private health insurance; risk selection; risk adjustment; long-term contracts

\section{Introduction}

A very important question concerning private health insurance markets is how to overcome the trade-off between the possibility of enforcing long-term insurance contracts on the one hand and the danger of risk selection on the other.

Premium regulations seem to be necessary to enforce long-term contracts in health insurance but they also lead to adverse incentives in competition. ${ }^{3}$ Even though insurers can identify the risks of the insured in the course of time they are not allowed to use this information to adjust premiums to the individual risk in long-term contracts. With competition, it would be the optimal strategy for profit-maximizing insurers to compete for good risks only, that is, for the insured with (the present value of) expected annual costs lower than (the present value of) annual insurance premiums. Resources are dedicated to the development of selection mechanisms aiming at the identification of good risks instead of the improvement of the efficiency

\footnotetext{
*The Paper was prepared with the financial support of the Otto-Wolff-Institute for Economic Studies, Cologne. We thank Nicole Blout, Sven Ramsey and two anonymous referees for their helpful comments.

${ }^{1}$ Meyer (1992).

${ }^{2}$ Ibid.

${ }^{3}$ Pauly (1984).
} 
and quality of health services provided. This risk selection causes a waste of scarce resources in health care.

For private health insurance markets, different approaches are discussed to enforce competition within a risk-rated framework and long-term-contracts. ${ }^{4}$ Guaranteed renewable contracts ensure competition only for low risks, while high risks suffer high financial losses if they cancel their policies after a few years. ${ }^{5}$ By contrast, premium insurance could lead to adverse incentives for the person insured and for the premium insurer, thus harming the health insurance company. Furthermore, it could be difficult to enforce necessary compensation payments from low risk insured to the insurance company if the contract were cancelled. ${ }^{6}$

Health insurance in the German private health insurance (phi) market can be seen as a combination of guaranteed renewable contracts and the ageing provision, a compulsory precautionary savings element. ${ }^{7}$ If an insured person switches to another insurance company, the pre-payment from guaranteed renewable contract as well as the ageing provision is not transferred to a new insurer. Thus, competition is limited to persons who enter into the insurance market for the first time. This paper provides an overview of the ongoing discussions regarding the feasibility of having more intense competition in the German phi-market. The authors will show that full competition in the health insurance market with long-term contracts can be achieved by relying on risk-rated insurance premiums and transferable risk-adjusted ageing provisions, as first proposed by Meyer. ${ }^{8}$

The paper is organized as follows: the following section gives an overview of the phimarket in Germany. The model of transferable risk-adjusted ageing provisions is then presented and afterward discussed in the next section. The penultimate section briefly deals with problems likely to occur if the described model were to be applied to the German health insurance system. Concluding remarks follow in the last section.

\section{The phi-market in Germany}

The German health insurance market is divided into two different branches. Most employees and their families are insured in one of about 300 sickness funds, which are part of the compulsory social insurance system. Employees with an income exceeding a certain limit as well as self-employed people and civil servants are allowed to opt for the second branch, the private health insurance market.

In Germany's private health insurance market long-term contracts are combined with risk-rated premiums. Premium increases due to a worsening change in the state of health are prohibited in current contracts. Premiums, which would rise in short-term contracts due to the increasing expected annual costs from the ageing of the person insured are offset by a precautionary savings element - the ageing provisions.

\footnotetext{
4 The question of how to design a market for long-term health insurance contracts was first considered by Arrow (1963, p. 964) and Pauly (1970, p. 411).

${ }^{5}$ Pauly et al. (1995).

${ }^{6}$ See Cochrane (1995) for details.

${ }^{7}$ See Kifmann (2000, p. 579) and Baumann et al. (2004).

${ }^{8}$ Meyer (1992).
} 
Premiums paid by the insured while young are slightly increased, thus making it possible to accumulate ageing provisions. When, later on in life, premiums no longer cover expected annual costs, the ageing provisions are reduced to cover excess costs.

There is little, if any, room for risk selection in such a market, since whenever a new policy is taken out, the insurer calculates a risk-rated premium that covers expected future costs. Premiums are calculated as follows: individuals with no noteworthy previous illnesses pay a standard rate. High-risk individuals pay a so-called risk loading, which constitutes a percentage of the standard rate. For some people coverage will even be denied. Once a private health insurance contract has been closed, the insurer may not cancel it, provided the insured person has given correct information regarding his health status at the time the contract has been closed. Unlike insurers, the insured person can cancel the policy. However, there is only little competition on the phi-market in Germany. The insured persons will rarely be in a position to change their provider once a contract has been closed, even if they are dissatisfied with the insurer. The reason is that any insured person who actually changes the original insurer loses his accumulated ageing provisions. When changing one's insurer, the accumulated money remains with the former provider. Thus, the insured will have to pay higher premiums to the new insurer, as the new premium will again be calculated based on the age and state of health at the time of applying for coverage. Changing the insurance provider will merely be an option for those who have only been insured for a short period of time and have, therefore, not been able to build up noteworthy provisions. This lock-in effect restricts competition to young and healthy insured. It also becomes difficult for new insurance companies to access the market. ${ }^{9}$

So why are ageing provisions not transferred? It is argued that transferable ageing provisions could encourage risk selection. If ageing provisions were the same for all members of the risk pool, insurance companies would have the incentive to pick the "good risks". Insurance companies that are successful at selecting "good risks" would thus receive relatively high ageing provisions compared to the insured's expected costs. The result would be an inefficient separation of risks, that is, risk selection. ${ }^{10}$ Another minor - more redistributive - argument often heard is that premiums for all the "loyal" insured would rise, as these people could no longer benefit from the ageing provisions withdrawn by the fraction of people that cancel a policy. ${ }^{11}$

\section{Transferable risk-adjusted ageing provisions}

The discussion about the feasibility of transferable ageing provisions is not new. Meyer ${ }^{12}$ first showed that efficiency gains would be possible if the ageing provisions

\footnotetext{
${ }^{9}$ It will be more difficult to attract enough customers to reach the number of insured necessary to pool risks efficiently.

${ }^{10}$ Unabhängige Expertenkommission (1996, p. 43).

${ }^{11}$ Some policies are cancelled within two years after a contract was closed, because the insured person receives a better offer from a competitor. If ageing provisions were transferable, the premiums towards the new insurer should be lower. The cancellation of a policy may also occur, because the insured person has dropped back into the compulsory social health insurance system, for example after changing jobs.

12 Meyer (1992).
} 
known from the German private health insurance market were adjusted to the individual risk and transferred in case of a switch of insurance providers. ${ }^{13}$ Consider the following case within a health insurance system as it has been described in the previous section for the private health insurance market in Germany: Once an insured person has been recognized or classified as a high risk, for example, due to an accident or a chronic disease, an average share of the total ageing provision will not cover the higher expected costs of future treatment anymore. As long as this person keeps his original contract with insurer A, other policyholders with lower risks will have to cover his higher expenditures within the risk pool. This is, indeed, the main purpose of long-term insurance contracts. But currently, a long-term insured who cancels his policy with insurer $\mathrm{A}$ and takes out a new policy with competitor B, has to pay noteworthy higher premiums to $\mathrm{B}$, although he was insured in a long-term contract, because his ageing provision cannot be transferred to the new contract. Thus, the long-term contracts within the German private health insurance system are not enforced completely. An insured high-risk person choosing to leave the present insurer will suffer a financial loss compared to a situation in which he continues his original contract.

In order to enforce long-term contracts, assume that insurer A has to transfer ageing provisions to insurer B. To avoid risk selection in this framework, it is then necessary to adjust ageing provisions according to changes in the state of health. Ageing provisions transferred to $\mathrm{B}$ covering low risks are lower than average, ageing provisions transferred to $\mathrm{B}$ covering high risks are higher than average. More technical, given the premium of insurer $A$ and the state of health of the insured $X$, the ageing provision will depict the difference between expected costs and expected future premiums of insured $\mathrm{X}$. The difference between the average ageing provision and the lower ageing provision of the low-risk insured can be interpreted as a compensation for the expected higher costs of the remaining high-risk insured. Only by compensating the old risk pool in the described manner, the low-risk insured who are about to switch providers actually cover the expected costs of the other (high-risk) insured remaining in the risk pool. ${ }^{14}$

If a high-risk insured cancels the policy with $\mathrm{A}$, a risk-adjusted ageing provision is transferred to B according to his higher expected costs. B's premium is calculated based on the new information regarding the insured's state of health and the accompanying (higher) ageing provision. Assuming perfect information and identical technology, premiums between different insurers do not differ in insurance market equilibrium. Dropping the assumption of identical technology, the premiums only differ due to different levels of efficiency in production and different quality of medical services provided by the insurer. In any event, they do not depend upon the state of health of the insured; long-term contracts thus can be enforced. ${ }^{15}$

The crucial questions, in an environment of incomplete information, are: Do the insurance companies have the possibility and are there incentives to miscalculate the

\footnotetext{
${ }^{13}$ See also Monopolkommission (1998), Sachverständigenrat (2002), Donges et al. (2002), Meier (2003), Eekhoff (2005).

14 This corresponds to the mechanism suggested by Cochrane (1995) to insure against premium risk.

15 Meyer (1992, p. 192 et seq.).
} 
ageing provisions? And do they have the necessary information to risk adjust ageing provisions? ${ }^{16}$ The following sections will show that the risk-adjustment of ageing provisions in the case of incomplete information is not only possible, but is also an efficient way of avoiding risk selection.

\section{Optimal risk-adjustment from an insurer's point of view}

If all insurers have enough information to adjust ageing provisions to the individual risk, there might still be the incentive to state that the insured person is rather healthy (or ill) and to miscalculate the ageing provision according to the documented state of health of the insured. This could be the case if the state of health and the related ageing provision are not litigable. ${ }^{17}$ Nevertheless, we will show that insurers have an interest in calculating the individual risk-adjusted ageing provision correctly.

\section{(a) Risk-adjustment of ageing provisions and quality of care}

First, we assume that all insurance companies supply the same quality of insurance and health care services. If a high-risk insured person $\mathrm{X}$ cancels his policy with insurer A, then insurer A will be indifferent between continuing the contract and transferring an ageing provision, only if the transferred amount equals the difference between the present value of expected future health care expenditures and the expected premiums. If insurer A encourages the high-risk insured person to cancel the policy by granting a higher provision, it would lose money. The insurer could also calculate a lower provision in order to gain a surplus if the insured person switches to another company. But X would have to pay a higher premium for his new policy with insurer B due to the small ageing provision and his high risk. $\mathrm{X}$ will, of course, only cancel the old policy if he has the opportunity to improve his situation. This is only possible if the premium for $\mathrm{B}$ is at least marginally lower than the premium formerly asked for by A. Knowing this, A will increase the ageing provision as long as this leads to a marginal return from the high-risk insured that actually do cancel their policies. The risk-adjusted ageing provision can, therefore, be seen as the price one has to pay to "get rid of" a (highrisk) ${ }^{18}$ insured. ${ }^{19}$ Assuming identical technology, the amount $\mathrm{A}$ is willing to transfer to $\mathrm{B}$ must be only marginally lower than the difference between expected future costs and expected future premiums of our insured person $\mathrm{X}$.

This result holds as long as the insurers do not have the possibility to provide different qualities of insurance services or health care, that is, as long as insurance is a homogenous good. Presuming that quality does matter, risk selection may well occur when canceling a policy if insurance companies are free to determine the ageing provisions at that point. Policyholders receiving a provision that is too low will only cancel their policies with A if they are sufficiently dissatisfied. To them, the burden of having to pay a higher premium to B would seem acceptable. A could foster such a

\footnotetext{
${ }^{16}$ See for example Meier (2003, p. 9).

17 Ibid.

18 The same mechanism applies to low-risk insured.

${ }^{19}$ See Meyer (1992, p. 197), and for a more detailed analysis Eekhoff (2005).
} 
situation by offering additional "incentives" in order to influence certain groups and thus make them switch. For instance, the quality of medical care or other services might be reduced in order to stimulate the insured's willingness to switch even at a higher price. $^{20}$

The insurer might well be able to identify those policyholders that are particularly concerned about health services. Within a managed care environment, for example, the insurance coverage provider could influence the risk selection process by providing no more than average quality in fields of particular importance to certain groups of insured persons. As an example, for young couples who would like to have children, the problem becomes obvious: These people are presumably interested in certain services, such as high quality of obstetrical or pediatric services and expect their insurer A to provide high-quality services. A on the other hand, can assume that the couple would be willing to accept an increase in insurance premium charged by a possible new insurer B, provided that they were sufficiently dissatisfied with A's services. The transfer of an ageing provision that is too low according to the state of health of the insured couple would bring A into an advantageous position: The policyholders can be influenced into leaving the risk pool, which company A obviously would not regret. The remaining sum of ageing provisions is likely to be higher than necessary to cover future costs of the remaining risk pool. Insurer A can use this surplus to reduce premiums for the remaining insured.

\section{(b) The "summation rule"}

The insurer's attitude and thus the practice described above might change in case the management sees itself exposed to the immediate risk of endangering the company's reputation. $^{21}$ A more reliable - although at the same time more expensive $e^{22}$ - solution of the risk selection problem is the "summation rule". The risk-adjusted ageing provision must be annually calculated for every insured person, while the sum of individual ageing provisions always has to equal the total ageing provision displayed in the balance sheet. If insurer A calculated an insured's ageing provision too low, insurer B would have to be all the more efficient in order to compensate the new policyholder for the missing amount of ageing provisions. If this were not the case, the insured person would most likely refrain from switching despite his being dissatisfied with A's service. After all, the new policy would obviously have to cost him more. But simultaneously, the ageing provisions calculated for the other customers remaining in A's risk pool would tend to be too high, as the sum of provisions should equal the balanced provision. This, in turn, could result in these remaining insured people canceling their policies with $\mathrm{A}$, as insurance coverage can be bought at lower premiums without requiring $\mathrm{B}$ to be more efficient. In addition, the remaining A-customers would have to accept rising premiums, as A could no longer cover all future costs due to the insufficient ageing provisions. Increasing premiums would

\footnotetext{
${ }^{20}$ See van de Ven and van Vliet (1992) and van de Ven (2001) for an overview of different risk selection strategies.

${ }^{21}$ See van de Ven (2001, p. 93), or Kifmann (2000, p. 578), applying this argument in similar contexts.

${ }^{22}$ Unabhängige Expertenkommission (1996, p. 46).
} 
again stimulate more policyholders to leave $\mathrm{A}$, as the differences in premiums between the two competitors would have declined or even disappeared. Thus, miscalculation of ageing provisions can indeed lead to the failure of an insurer within the competitive process. ${ }^{23}$

If this "summation rule" is monitored by a third-party regulation authority or through outside accountants, incentives to miscalculate ageing provisions are abolished. Quality of the supplied services might still vary, however these differences will be depicted in different premiums, and they leave no room for risk selection. It then becomes impossible to exploit the higher willingness to pay for certain services through miscalculated ageing provisions.

\section{(c) The total amount of the ageing provision}

Insurer A can also make an effort to reduce the amount of the balanced ageing provision to an insufficient level in order to circumvent the illustrated summation rule. A sufficiently high ageing provision for the entire risk pool is necessary to cover increasing health expenditures in an ageing risk pool. If A calculates an ageing provision lower than necessary to avoid a future increase in premiums, two consequences are likely to follow: First, if A calculates lower provisions in order to attract more policyholders by charging a lower premium, the initial competitive advantage can be expected to vanish after a short period, as ageing provisions will soon be insufficient and not cover the costs caused by the elderly. It follows that premiums will soon have to be increased. Second, A might balance a smaller ageing provision than necessary in order to make a short-term surplus or to keep customers from canceling their policies. If A charges the same premium as its competitor B which is necessary in order to provide for future costs in another way, for example by allocating money to the surplus reserve - B will compete for new applicants by offering a higher quality of services combined with either lower premiums or higher ageing provisions. The conclusion drawn from this model can only be that calculating with insufficient provisions to cover future costs is not a suitable strategy when striving for success in a competitive market.

This result holds at least as long as the policyholders are interested in a long-term health insurance contract. But what happens if the insured are not willing to pay the higher premiums required by long-term contracts, assuming that they will be healthier than the average policyholder in the future? What if the consumer chooses to consume other goods rather than insurance coverage, that is, cars or holidays? In fact, in this situation both the insured and the insurer are interested in very low contributions to the ageing provisions. The provision will be too low to cover age-related premium increases in the future. But even assuming that the insurers did not calculate any ageing provision at all, within long-term contracts the mechanism of risk-adjustment would still function. A "low risk" canceling a policy will have to pay a compensation covering the present value of the expected premiums exceeding the present value of the individual expected health expenditures. On the contrary, a "high risk" will receive payments as a form of compensation for health expenditures higher than average. ${ }^{24}$

\footnotetext{
${ }^{23}$ See Donges et al. (2002, p. 53).

${ }^{24}$ See Cochrane (1995).
} 
However, ageing provisions could remain necessary for two further reasons. First, as Cochrane ${ }^{25}$ already stated, one might face legal problems when forcing low-risk policyholders into paying compensation to the insurer once a cancellation has been requested. This problem could be ruled out by applying ageing provisions. They would, even for good risks, turn positive after only a short period of time. It must, however, be emphasized, that this is merely a legal problem. From an economic point of view a competing insurance company would be able to offer a lower premium or - at equal prices - to pay the necessary compensation to the old insurance.

The second reason why ageing provisions could stay necessary is that one might require a means to avoid the exploitation of the social welfare system. If social welfare institutions paid for health insurance or for health care expenditures, policyholders might exploit the system by consuming other goods rather than paying for their ageing provisions. ${ }^{26}$ Assuming that the costs of free-riding on the social welfare system are higher than the costs of limiting the consumer choice, the definition of a minimum contribution to ageing provisions becomes necessary. ${ }^{27}$

\section{Risk-adjustment and information requirements}

It is highly unlikely that an insurer is capable of gathering full information on an individual's state of health and the corresponding expected future costs. But the calculation of risk-adjusted ageing provisions requires knowledge of the expected average costs for different risk classes. Some authors doubt the possibility of gathering the information required for the calculation of risk-adjusted ageing provisions. ${ }^{28}$ Nevertheless, such a shortage of information can be solved. First of all, private insurance companies in Germany have been able to gain a high level of experience calculating risk-rated premiums. In this context, they have already been working with ageing provisions for different risk-classes.

Furthermore, if risk selection associated with the portability of an average part of the ageing provisions is identified as a serious problem by the insurance companies, they must obviously already be able to calculate the difference of the present values of future expenditures and of future premiums for different risks. Otherwise, they would not be able to classify certain individuals as good or bad risks, given the amount of the average ageing provision.

It is not even necessary to differentiate the risk-adjustment of ageing provisions as far as possible. Imagine a situation where insurer A knows that the transfer of an average part of the ageing provision will lead to risk selection. Insurer A also knows that it can easily define three different risk classes - low, average and high risk. Furthermore, it has a bundle of selection criteria by which to assign the customers to

25 Ibid.

${ }^{26}$ See Hayek (1960, p. 286).

${ }^{27}$ A 10 per cent premium loading in $\S 12$ Abs. 4a VAG (insurance supervision act) was adopted in 2000 in order to reduce premium increases for insured more effectively, because a lot of retirees could not afford the increasing health insurance premiums in the German phi-market any longer. See also Unabhängige Expertenkommission (1996, p. 12).

${ }^{28}$ Ibid. p. 46, Meier (2003, p. 15). 
one of these risk classes. The optimization problem for A is whether it is cheaper to search for a more differentiated classification system or to bear the cost of remaining incentives to "skim the cream" for insurer B. A trade-off will always exist between the costs of a more exact differentiation of risks aiming at minimizing the danger of risk selection on the one hand, and rising costs caused by increasing differentiation on the other. The point of optimal differentiation has been reached once the marginal costs of these two types of costs become equal. Thus, given the cost of risk adjustment, insurance companies will adjust the ageing provisions to the individual risks as far as necessary to avoid risk selection efficiently.

However, there might be comparatively little information about future costs of different diseases in the German phi-market. But if the described model were to be introduced, insurance companies would be forced to calculate more precisely. This also includes the collecting of further information and the promotion of additional surveys on how current diseases and future health care expenditures within an insured group are connected. ${ }^{29}$

\section{Application to the German health insurance system}

\section{Reforming the phi-market in Germany}

Applying the model to the German phi-market should be rather easy. A reform of the existing insurance supervision act could force insurance companies to transfer riskadjusted ageing provisions. As ageing provisions do, in fact, already exist the method of calculation would merely have to be adapted to the new rules. For example, the currently exercised calculation method ${ }^{30}$ to withhold ageing provisions as a form of cancellation fee (when a policy is cancelled) could not be used any longer. So far, reallocating this cancellation fee within the remaining business in force leads to redistribution from the unsatisfied customers to those who hold their contract. So the technique of actually transferring ageing provisions would, in the short run, have to lead to increasing premiums for those policyholders who stick with the original supplier. ${ }^{31}$ On the other hand, it can be reasonably assumed that efficiency gains will compensate at least for a part of these premium increases in the long run.

Possibly, it could also become necessary to reconsider the way a risk loading is included in the calculation. A simulation of premiums in a model with risk-adjusted ageing provisions has shown that - given some very specific assumptions - higher risks would have to bear higher premium increases, for example due to technological progress, if they had switched to another insurance company before. Anticipating those premium increases, they could have been better off if they had not cancelled their old contract. ${ }^{32}$ These findings are dependent on the initial assumption that standard rates and additional risk loadings for high risks are calculated in the current manner. This problem should be solved, if the calculation method is adapted to the new requirements.

\footnotetext{
${ }^{29}$ See also Monopolkommission (1998, p. 343).

${ }^{30} \mathrm{See} \S \S 2$ and 5 of the Kalkulationsverordnung (Calculation Ordinance).

${ }^{31}$ Meyer (1992, p. 193).

${ }^{32}$ Milbrodt (2004).
} 
From this theoretical point of view, the transfer of risk-adjusted ageing provisions seems to be possible. As the necessary reforms within the German phi-market are limited to some minor changes in relevant law and calculation methods, it is remarkable why they have not taken place so far. This question could be highly interesting from a public choice perspective and, thus, for further research in this direction. ${ }^{33}$

\section{Reforming the social health insurance (shi) market in Germany}

Contributions within the compulsory social insurance system (sickness-funds) are community-rated and income-related. Low-income earners or senior citizens pay a lower contribution than high-income members. Spouses and children without an income of their own are insured in the same sickness funds as the sole earner without paying additional contributions. Community-rating as well as the income dependency of contributions make it necessary to run a risk-adjustment scheme. Otherwise risk selection could take place in order to attract relatively young, healthy, and highincome individuals. The "risk structure adjustment"-scheme attempts to compensate sickness funds for disadvantages in the risk structure and the income level of their members. Differences in the average income of the insured are adjusted as well as differences in age, gender or disability. This adjustment scheme has, however, proved to be insufficient, as it does leave room for the selection of relatively healthy insured. ${ }^{34}$ It was, therefore, decided to improve the risk adjustment scheme by adding healthrelated adjustment factors such as diagnostic findings and prescription of pharmaceuticals. The new system is supposed to be operative from 2007 onwards. ${ }^{35}$

The new system has been criticized for efficiency shortcomings and for distributive reasons. ${ }^{36}$ The risk-structure adjustment scheme would not be able to completely avoid inefficiencies because it is difficult for the regulator to overcome the trade-off between risk selection and inefficiently high costs of risk-adjustment. ${ }^{37}$ Furthermore, the sickness funds are not funded. A young insured person will pay a contribution higher than the average health expenditure within his age group. And an elderly person will pay contributions lower than the average health expenditures within his age group. So there is a direct transfer from the young to the elderly. In times of declining birth-rates, this must lead to rising contributions. It follows that this system is not sustainable in such a way that every generation pays the same amount of money for the same services. ${ }^{38}$

${ }^{33}$ This analysis is beyond the scope of this paper. See for some arguments Jankowski (2006). It seems that the initial reason why ageing provisions are not transferred was to avoid an "excessive" competition for insured, who are already customer of a phi-company. See Terhorst (2000) for further references and for a historical view on the evolution of the phi-market in Germany.

${ }^{34}$ Cassel et al. (2001).

${ }^{35}$ Busse and Riesberg (2004, p. 196). The currently discussed proposals for a reform of the shi in Germany must remain unconsidered.

${ }^{36}$ An overview over the discussion about the reform of the shi-market in Germany is provided for example by Breyer (2005).

${ }^{37}$ See Selden (1998, p. 175).

${ }^{38}$ See Hagist et al. (2005) for an analysis of the influence of an ageing society on the sustainability of shimarkets and of fiscal policy in four countries. 
Given these problems, some authors regard the model of transferable risk-adjusted ageing provisions also as an option to reform the shi-market in Germany. ${ }^{39}$ But transforming the sickness fund system into a competitive private health insurance market would in any event - at least politically - be considerably more complex. Two minor points are the separation of insurance and redistribution ${ }^{40}$ as well as problems likely to occur when trying to transform publicly governed corporations into private companies. The concept of risk-adjusted ageing provisions should then replace the risk-structure-adjustment scheme. In the course of these changes differences in historically developed risk-structures of the sickness funds must be considered.

The main difficulties concerning such a transformation are the implicit debts of the pay-as-you-go financed social system in Germany. While premiums in a pay-as-you-go system are reduced by the contributions of the future generations in a funded system each insured builds precautionary savings. Thus, when switching from a pay-as-yougo system to a funded system, one would have to satisfy the claims of today's contributors by means of a sufficiently high capital stock. Therefore, it would be necessary to transform the implicit debt of the sickness funds into a public debt. The capital stock itself would have to be available at a certain time, that is, the moment when sickness funds are changed into the legal form of a private company. Financing of this capital stock will in any event be challenging for efficiency and distributive reasons. The question of which generation will have to amortize the public debt must be answered. This again will presumably be a difficult task for political-economic reasons. What kind of impact does the transformation of implicit debt into public debt have on the efficiency of capital markets? Last but not least it must be taken into account that Germany has already violated the public debt criteria of the Maastricht treaties for several years.

These problems remain unsolved so far. But despite the difficulties one should always keep in mind that these claims will have to be paid anyway. In case of a reform the public debt will increase. However, the new system would not be as dependent on demographic changes as the old one is. And the mechanism of risk adjustment avoids remaining inefficiencies of the application of risk-structure-adjustment schemes. In case of remaining in the pay-as-you-go system contribution rates will increase or the benefit package will have to be restricted. In that respect the model reconsidered in this paper could - theoretically - be a considerable option when reforming the shi-market in Germany.

\section{Conclusion}

The paper has outlined the current discussion on the transferability of ageing provisions in the phi-market in Germany. The model of transferable risk-adjusted ageing provisions was reconsidered. It allows for competition between health insurers,

\footnotetext{
${ }^{39}$ See for example Donges et al. (2002) and Jankowski (2006).

${ }^{40}$ Breyer (2005).
} 
committing them to calculate risk-adjusted, portable ageing provisions. Counterarguments regarding the main criticisms of the model were presented. Although many authors emphasize that the model could theoretically lead to efficiency gains on health insurance markets, there are doubts whether it can be implemented. A common argument is that the correct amount of risk-adjusted ageing provisions is not litigable, as there are too many possibilities to miscalculate the individual provisions. It was shown that, within an appropriate regulatory framework, there are no incentives for insurers to miscalculate ageing provisions in a competitive process. It was also shown that it is not necessary to attain complete information on future costs of all possible diseases in order to avoid risk selection efficiently. Therefore, it can be assumed that the implementation of transferable ageing provisions constitutes more of a political problem than a practical one.

The model could indeed be applied to the phi-market as well as the shi-market. Nevertheless, the transformation of the German shi-market would without doubt be challenging for efficiency and distributive reasons. Political economic obstacles add to the complexity, making the reform within the shi-market even less probable.

\section{References}

Arrow, K.J. (1963) 'Uncertainty and the welfare economics of medical care', American Economic Review 53(5): 941-973

Baumann, F., Meier, V. and Werding, M. (2004) Transferable Ageing Provisions In Individual Health Insurance Contracts, CESIfo Working Paper No. 1116, München.

Breyer, F. (2005) 'How to finance social health insurance: Issues in the German reform debate', The Geneva Papers on Risk and Insurance - Issues and Practice 29(4): 679-688.

Busse, R. and Riesberg, A. (2004) Health Care Systems in Transition: Germany, Copenhagen: European Observatory on Health Care Systems.

Cassel, D., Jacobs, K., Reschke, P. and Wasem, J. (2001) Zur Wirkung des Risikostrukturausgleich in der Gesetzlichen Krankenversicherung - Eine Untersuchung im Auftrag des Bundesministeriums für Gesundheit (On the impacts of the risk structure adjustment in the German social health insurance market), IGES, Berlin.

Cochrane, J.H. (1995) 'Time-consistent health insurance', Journal of Political Economy 103(3): 445-473.

Donges, J.B., Eekhoff, J., Franz, W., Möschel, W., Neumann, M.J.M. and Sievert, O. (Kronberger Kreis) (2002) Mehr Eigenverantwortung und Wettbewerb im Gesundheitswesen, Schriftenreihe der Stiftung Marktwirtschaft - Frankfurter Institut Bd. 39 (Towards more personal responsibility and competition in health care, Studies of the Kronberger Kreis No. 39), Berlin.

Eekhoff, J. (2005) 'Übertragbare Altersrückstellungen in der privaten Krankenversicherung' (Transferable ageing provisions in the phi-market), Zeitschrift für Wirtschaftspolitik 54: 52-68.

Hagist, C., Klusen, N., Plate, A. and Raffelhüschen, B. (2005) Social Health Insurance - The major driver of unsustainable fiscal policy?, Discussion Paper No. 1, Research Center for Generational Contracts, Freiburg University.

Hayek, F.A.v. (1960) The Constitution of Liberty, London: Routledge.

Jankowski, M. (2006) Wettbewerb, Versicherungspflicht und Risikoanpassung - Zur Begründung und Gestaltung einer obligatorischen Krankenversicherung in der Wettbewerbsordnung (Competition, compulsory insurance and risk adjustment), Cologne: Institut für Wirtschaftspolitik.

Kifmann, M. (2000) 'The premium risk problem in health insurance', Schmollers Jahrbuch 120: 567-586.

Meier, V. (2003) Efficient Transfer of Ageing Provisions in Private Health Insurance, CESifo Working Paper No. 862, Munich.

Meyer, U. (1992) 'Zwei überflüssige Wettbewerbshemmnisse in der privaten Krankenversicherung' (Two superfluous limitations of competition within the private health insurance market), in T. Bock (ed.) 
Sozialpolitik und Wissenschaft (Social Policy and Science), Frankfurt am Main: Deutscher Verein für öffentliche und private Fürsorge, pp. 185-202.

Milbrodt, H. (2004) 'Wird es ernst? Zur Portabilität der Altersrückstellungen in der PKV' (About the portability of ageing provisions in the phi-market), Der Aktuar 10: 137-145.

Monopolkommission (1998) Marktöffnung umfassend verwirklichen, The Twelfth Biennial Report 1996/1997 by the Monopolkommission (Monopolies Commission), Baden-Baden.

Pauly, M.V. (1970) 'The welfare economics of community rating', Journal of Risk and Insurance 37(3): 407-418.

Pauly, M.V. (1984) 'Is cream-skimming a problem for the competitive medical market?' Journal of Health Economics 3(1): 87-95.

Pauly, M.V., Kunreuther, H. and Hirth, R. (1995) 'Guaranteed renewability in insurance', Journal of Risk and Uncertainty 10(2): 143-156.

Sachverständigenrat zur Begutachtung der gesamtwirtschaftlichen Lage in Deutschland (2002) Zwanzig Punkte für Wachstum und Beschäftigung - Jahresgutachten 2002/2003 (Annual Report 2002/03 of the German Council of Economic Experts), Stuttgart.

Selden, Th.M. (1998) 'Risk adjustment for health insurance: Theory and implications', Journal of Risk and Uncertainty 17(2): 167-180.

Terhorst, E. (2000) Wahlfreiheit und Wettbewerb in der Privaten Krankenversicherung (Freedom of choice and competition within the phi-market), Berlin: Erich Schmidt Verlag.

Unabhängige Expertenkommission (1996) Gutachten der Unabhängigen Expertenkommission zur Untersuchung der Problematik steigender Beiträge der privat Krankenversicherten im Alter (Report of the Independent Commission of Experts for the analysis of increasing premiums in private health insurance), Drucksache 13/4945 des Deutschen Bundestages (Printing 13/4945 of the Lower House of German Parliament).

Van de Ven, W.P.M.M. (2001) 'Risk selection on the sickness fund market', European Journal of Health Economics (HEPAC) 2: 91-95.

Van de Ven, W.P.M.M. and van Vliet, R.C.J.A. (1992) 'How can we prevent cream skimming in a competitive health insurance market? The great challenge for the 90's', in P. Zweifel and H.E. Frech III (eds.) Health Economics Worldwide, Dordrecht, NL: Kluwer Academic Publishers, pp. 23-46.

\section{About the Authors}

Johann Eekhoff is Professor for Economic Policy at the University of Cologne and former state secretary of the Federal Ministry of Economics.

Markus Jankowski studied economics at Konstanz University and was a Research Assistant at the Economic Policy Department of the University of Cologne until March 2005.

Anne Zimmermann studied economics at Bonn University and is currently Research Assistant at the Economic Policy Department of the University of Cologne. 